
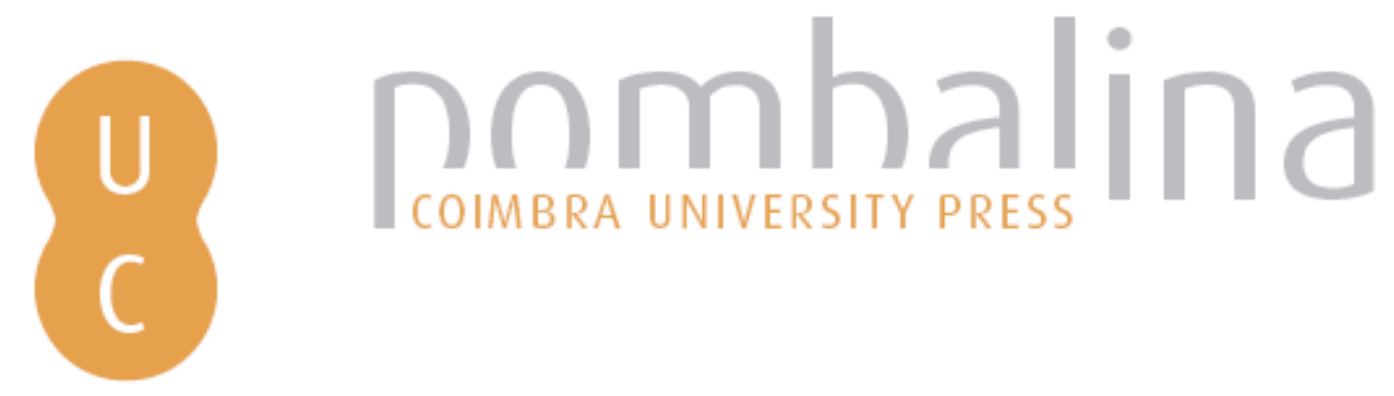

\title{
Validation of the burned area "(V,W)" Modis algorithm in Brazil
}

$\begin{array}{ll}\text { Author(s: } & \text { Libonati, Renata; DaCamara, Carlos C.; Setzer, Alberto W.; Morelli, } \\ \text { Fabiano; Jesus, Silvia C. de; Candido, Pietro A.; Melchiori, Arturo E. }\end{array}$

Published by: Imprensa da Universidade de Coimbra

Persistent URL: URI:http://hdl.handle.net/10316.2/34074

DOI: $\quad$ DOI:http://dx.doi.org/10.14195/978-989-26-0884-6_197

Accessed : $\quad$ 9-Dec-2014 11:24:46

The browsing of UC Digitalis, UC Pombalina and UC Impactum and the consultation and download of titles contained in them presumes full and unreserved acceptance of the Terms and Conditions of Use, available at https://digitalis.uc.pt/en/terms_and_conditions.

As laid out in the Terms and Conditions of Use, the download of restricted-access titles requires a valid licence, and the document(s) should be accessed from the IP address of the licence-holding institution.

Downloads are for personal use only. The use of downloaded titles for any another purpose, such as commercial, requires authorization from the author or publisher of the work.

As all the works of UC Digitalis are protected by Copyright and Related Rights, and other applicable legislation, any copying, total or partial, of this document, where this is legally permitted, must contain or be accompanied by a notice to this effect. 


\section{ADVANCES IN}

Forest Fire

\section{RESEARCH}

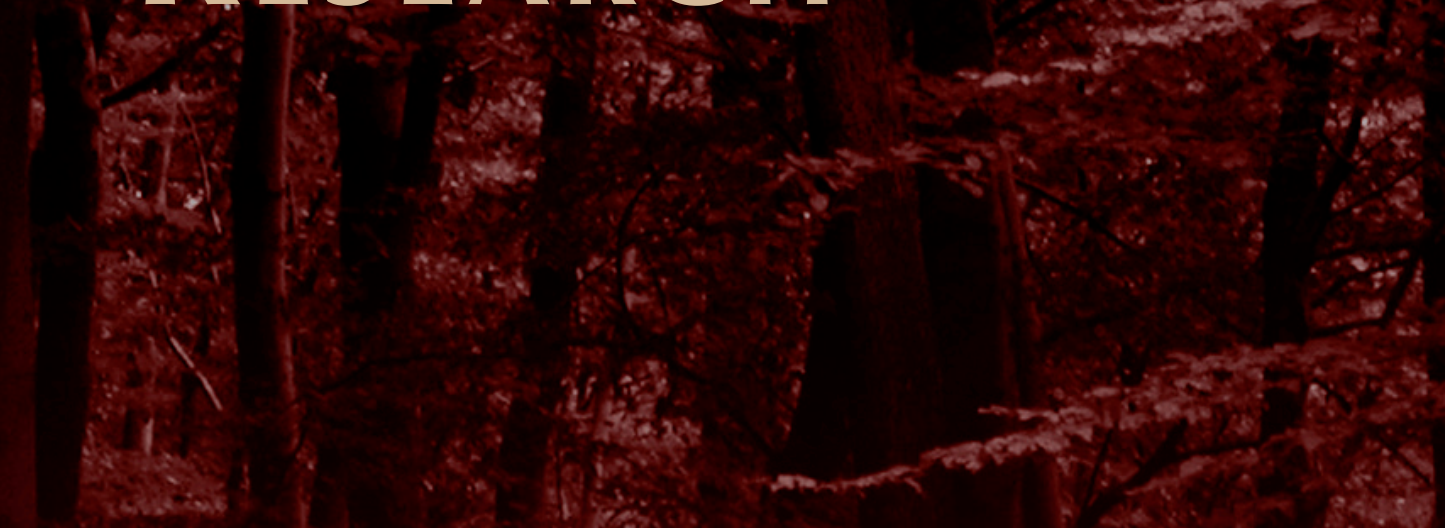

\section{DOMINGOS XAVIER VIEGAS}

\section{EDITOR}




\title{
Validation of the burned area " $(\mathrm{V}, \mathrm{W})$ " Modis algorithm in Brazil
}

\author{
Renata Libonati ${ }^{\mathrm{a}}$, Carlos C. DaCamara ${ }^{\mathrm{b}}$, Alberto W. Setzer ${ }^{\mathrm{a}}$, Fabiano Morellia ${ }^{\mathrm{a}}$, Silvia C. de Jesus ${ }^{\mathrm{a}}$, \\ Pietro A. Candido ${ }^{\mathrm{a}}$, Arturo E. Melchiori ${ }^{\mathrm{a}}$ \\ ${ }^{a}$ Instituto Nacional de Pesquisas Espaciais, Cachoeira Paulista - SP, Brazil - \\ renata.libonati@cptec.inpe.br; alberto.setzer@cptec.inpe.br; fabiano.morelli@cptec.inpe.br; \\ silvia.jesus@cptec.inpe.br; pietrocandido@cptec.inpe.br, emelchiori@gmail.com@cptec.inpe.br \\ ${ }^{b}$ Instituto Dom Luiz / Universidade de Lisboa, Lisboa, Portugal - cdcamara@fc.ul.pt
}

\begin{abstract}
This work presents an automated regional algorithm that allows detecting burned areas in Brazil based on information from TERRA/AQUA MODIS data. The procedure relies on the so-called $\mathrm{W}$ burning index, that requires daily reflectance from the $1 \mathrm{~km}$ MODIS Level $1 \mathrm{~B}$ calibrated radiance from bands 2 (near infrared) and 20 (middle infrared). Burned pixels are first identified as those located in the neighbourhood of active fires and associated to values of $\mathrm{W}$ and temporal changes in $\mathrm{W}$ larger than a fixed threshold. Pixels in the neighbourhood of the previously identified ones are then tested as burned ones based on contextual tests performed on associated values of $\mathrm{W}$ and temporal changes in $\mathrm{W}$. Validation of results was performed over Cerrado region using high resolution burned area maps derived from Landsat imagery, paying special attention to the omission and commission errors. For comparison, validation of NASA/MODIS burned area products MCD45A1 and MCD64A1 is also carried out over the same area. Results from the new algorithm present considerably lower omission error when compared to NASA/MODIS products. The two NASA products present very low commission errors (ranging from 2 to $10 \%$ ) but they are affected by very high occurrence of omission errors (greater than $60 \%$ in almost all cases analysed). The new product has larger commission errors (ranging from 20 to $40 \%$ ) but a large fraction of those (more than 40\%) occur at the borders of the scars and may therefore not be strictly viewed as false alarms; there is also a clear reduction of the omission cases (below $40 \%$ in all cases).
\end{abstract}

Keywords: Burned areas, MODIS, remote sensing.

\section{Introduction}

In Brazil, the conversion of vegetation into pasture and agricultural land using fire practices is a key source of greenhouse gases and trace gases to the atmosphere. Besides, lower moisture conditions enable the use of fire as a tool for land management during the dry season. Furthermore, fire used for burning crops and pastures frequently goes beyond control affecting neighbouring vegetation and becoming a major concern due to the potentially vast area of vegetation affected.

Despite the explicit vulnerability for fire of Brazilian ecosystems, together with the unequivocal need for reliable fire information, to the best of our knowledge hardly any products were developed to operationally monitor burned area in the Brazilian ecosystems. This issue is of particular interest since the accuracy of burned area (BA) maps is closely related to the specific characteristics of a given region (e.g., pre-fire land-cover type and conditions, background soil, fire severity, post fire processes and atmospheric conditions).

The aim of the present work is to develop an automated regional algorithm that allows detecting burned areas in Brazil based on information from TERRA/AQUA MODIS data. The procedure relies on the so-called W burning index (Libonati et al., 2011), that uses daily reflectance as obtained from the $1 \mathrm{~km}$ MODIS Level 1B calibrated radiance from band 2 (near infrared - NIR) and band 20 (middle infrared - MIR). Burned area pixels in the images are first searched in the neighbourhood of active fires, selecting the pixels where specific thresholds of $\mathrm{W}$ and of temporal $\mathrm{W}$ changes are exceeded. Pixels in the neighbourhood of the previously identified ones are then considered as burned pixels based on contextual tests performed on associated values of $\mathrm{W}$ and respective temporal changes. Validation of 
results is performed over Cerrado region using high resolution BA maps as derived from Landsat imagery, paying special attention to the omission and commission errors. For purposes of comparison, a similar validation of NASA/MODIS BA products MCD45A1 and MCD64A1 is also carried out over the same area.

\section{Data}

Calibration data consist of top of the atmosphere (TOA) values of MIR radiance, NIR reflectance and thermal-infrared (TIR) brightness temperature, as acquired by the MODIS instrument on-board TERRA and AQUA satellites. Data were extracted from the TERRA/AQUA MODIS Level 1B $1 \mathrm{~km}$ V5 product, MOD021/MYD021 (MCST, 2006) and correspond to channels 2 (NIR, centered at 0.858 $\mu \mathrm{m}), 20$ (MIR, centered at $3.785 \mu \mathrm{m}$ ) and 31 (TIR, centered at $11.017 \mu \mathrm{m}$ ). Geolocation data as well as land/sea mask and solar and view angle information for each MODIS 1-km sample were obtained from the MODIS Geolocation product (MOD03 and MYOD03). Both MODIS Level 1B $1 \mathrm{~km}$ V5 and MODIS Geolocation products were obtained from the Image Generation Division (DGI) of the Brazilian National Institute for Space Research (INPE). DGI/INPE is responsible for, among other satellites and sensors, the reception, processing and distribution of MODIS images acquired by TERRA and AQUA satellites and the products are made available in Hierarchical Data Format (HDF) format. It may be noted that all MODIS products mentioned above are also free available via the MODIS website.

Information about active fires was based on data provided by GOES, NOAA, MSG-2, TRMM, ATSR, AQUA and TERRA satellites. Data were acquired from INPE active fire database.

Results obtained in the present work were compared with reference BA data as derived from Landsat TM imagery over Jalapão, a region located in the state of Tocantins (Figure 2). The BA scars dataset was derived using a semi-automatic algorithm developed at INPE and the results were verified by independent analysts. The methodology is based on multi-temporal compositing of Landsat imagery and priority is given to select cloud free images less than 32 days apart. The periods covered by the BA dataset July-August 2005, June-September 2006 and June-September 2010. The study region covers about $187 \times 187 \mathrm{~km}^{2}$ and lies within Landsat TM paw/row 221/67. The region belongs to the Cerrado biome and has been increasingly affected by fire in the last years. For instance, during the 2010 dry season, Jalapão has accounted for $60 \%$ of all fire events detected in the Cerrado biome.

Results were further compared with those from the two MODIS BA official products namely the MCD45A1 Burned Area Product (Roy et al., 2005) and MCD64A1 Direct Broadcast Monthly Burned Area Product (Giglio et al., 2006). MCD45A1 and MCD64A1 BA products were freely downloaded from the University of Maryland ftp sites. Tiles for the two BA products over Brazil between 2005 and 2010 were then mosaicked and remapped using the Modis Reprojection Tool.

MCD45A1 is a monthly Level 3 gridded $500 \mathrm{~m}$ product containing per-pixel burning and quality information, and tile-level metadata. Quality information is given using five confidence levels of detection from 1 (most confident) down to 4 (least confident). Confidence level 5 denotes detections over agricultural areas, as identified by the MCD12 land cover mask. As stated in MODIS Collection 5.1 - Burned Area Product - MCD45 User's Guide, level 5 detections should not be used in any quantitative analysis because of the low accuracy of BA detection when fire is due to agricultural practices. The MCD45A1 Science Data Sets used in our analysis include all quality assurance flags from 1 to 4.

MCD64A1 is globally available on a monthly basis back to August 2000 at 500m resolution. The MCD64A1 Direct Broadcast Monthly Burned Area Product is currently used in the framework of the Global Fire Emissions Database (GFED) initiative and will replace MCD45A1 in the upcoming MODIS Collection 6. Among the five data layers from MCD64A1, only the Burn Date was used in our study, as this product does not have flags containing confidence levels. 


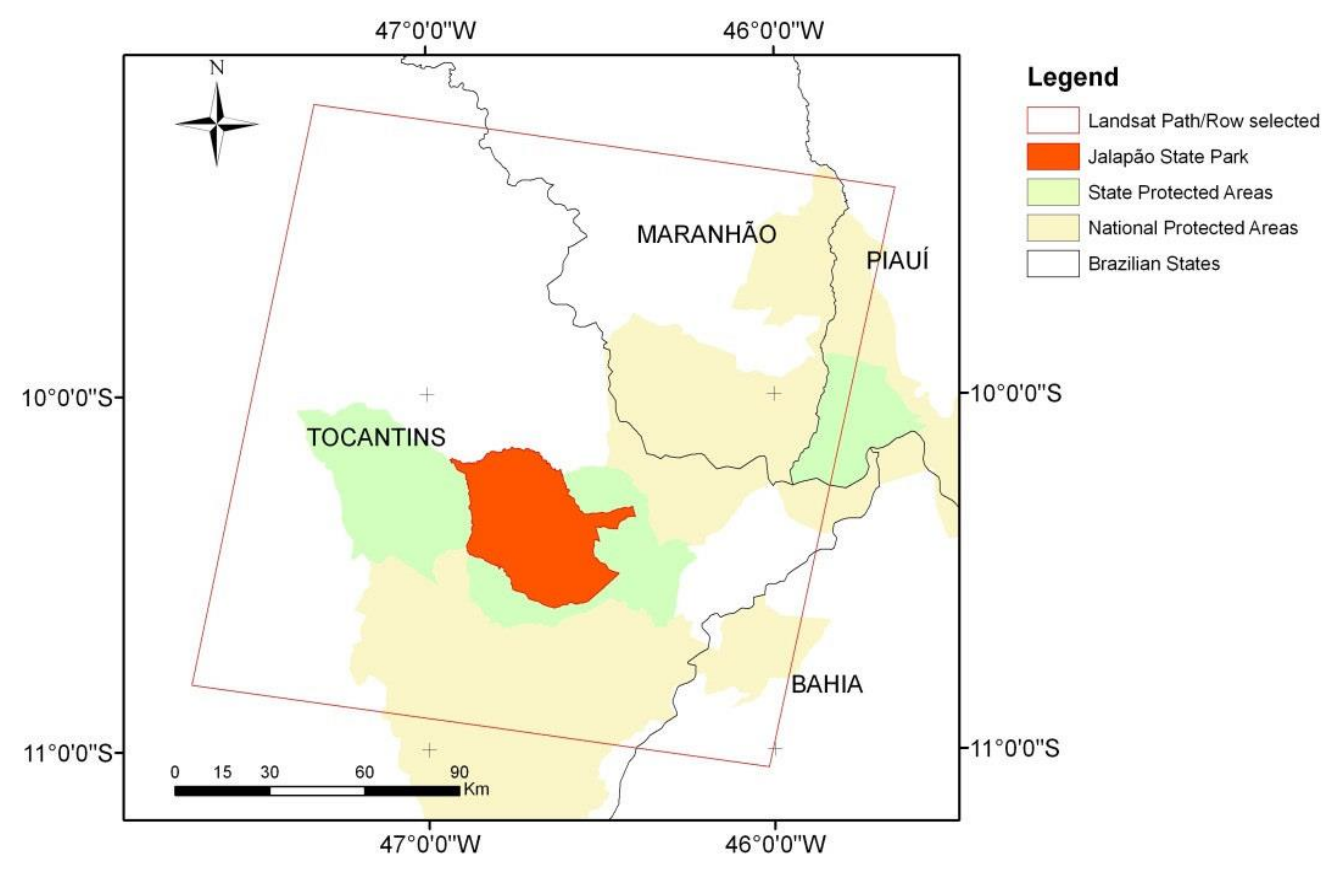

Figure 1. Location of the validation site of Jalapão in the state of Tocantins.

\section{Methods}

\subsection{Pre-processing}

Values of MIR reflectance were retrieved from MODIS channel 20 (MIR) radiances by applying to daytime imagery the methodology developed by Kaufman and Remer (1994) and using TIR (MODIS channel 31) brightness temperature as a surrogate for land surface temperature. Following Libonati et al. (2011), special attention was paid to the presence of high solar zenith angles (SZA), all images acquired at solar zenith angles greater than $55^{\circ}$ having been rejected. When TERRA and AQUA images were both available for the same day, the image selected was the one with the lowest SZA. Images with view zenith angles (VZA) greater than $45^{\circ}$ were also rejected in order to prevent large distortions in pixel size. Pixels associated to water bodies were also masked using the land/sea mask from the MODIS Geolocation product (MOD03, MYD03).

As discussed in Libonati et al. (2011), burned surfaces tend to have values of W very close to zero, especially shortly after the fire event, whereas green vegetation tends to be characterized by higher values of $\mathrm{W}$ (about 0.3 ). Intermediate values of $\mathrm{W}$ generally correspond to vegetation of small density and/or to the emergence of the soil background. Clouds and cloud shadows are often associated to high values of $\mathrm{W}$ (greater than 0.4 ). We have accordingly rejected pixels associated to $\mathrm{W}$ values greater than 0.4 , which were flagged as contaminated by clouds/shadows.

\subsection{Temporal composites}

Multi-temporal image compositing is an operational means of mitigating the gap of information about the land surface due to the presence of cloudy pixels which is especially high in the tropics (Sousa $e t$ al. 2003). Compositing also contributes to reducing the daily reflectance variability and residual atmospheric effects (Holben et al., 1986). Compositing techniques have been therefore widely used for BA detection (Barbosa et al., 1998; Stroppiana et al., 2002; Sousa et al., 2003; Stroppiana et al., 2003; Chuvieco et al., 2008). 
Following these approaches, monthly minimum composites of $\mathrm{W}$ were computed, the chosen span of one month representing a compromise between the need to retain the burned signal and the requirement of having a reasonable number of pixels to generate a meaningful minimum value of $\mathrm{W}$.

\subsection{Selection of burned pixels (stage I)}

Identification of burned pixels is performed in two stages. First (stage I), the analysis is restricted to pixels belonging to $3 \times 3$ pixel buffer zones centred in pixels where active fires were identified during the compositing period. Information on active fires is extracted from the INPE database (see http://www.dpi.inpe.br/proarco/bdqueimadas/) as obtained from data provided by GOES, NOAA, MSG-2, TRMM, ATSR, AQUA and TERRA satellites. The defined buffer may be viewed as an area of influence/coverage of the identified active fires, taking into account that we are using data with different spatial resolutions (e.g. $3 \mathrm{~km}$ for MSG/SEVIRI, $1 \mathrm{~km}$ for TERRA/MODIS).

As pointed out by Giglio et al. (2006), algorithms aiming at BA detection based on active fire detection (Roy et al. (1999), Fraser et al. (2000), Pu et al. (2004), George et al. (2006), Loboda et al. (2007)) may fail to uncover burned areas due to active fire omissions either because of the time of satellite overpass or due to obscuration by clouds, smoke and vegetation. Schroeder et al. (2008) have quantified the impact of cloud obscuration on GOES active fires in the Brazilian Amazonia. They showed that in some regions $15 \%$ of GOES active fires were omitted due to cloud cover. When assessing fire continuity over time and space, Schroeder et al. (2005) suggest the integration of multiple datasets in order to reduce the uncertainties in fire counts when derived using a single system. Giglio et al. (2009) also pointed out that BA detection may benefit from the fusion of multi-sensor active fire observations. We therefore believe that the problems associated to active fire omissions are considerably mitigated by relying on information on hot spots from a collection of sensors on board different satellites.

Pixels in the $3 \times 3$ buffer zone are then classified as burned ones when there is a change in $\mathrm{W}$ between monthly composites that is likely to have been induced by a fire event. It is worth mentioning that in stage I, such changes in $\mathrm{W}$ have to be large enough so that possible contaminations by active fire commission errors (false alarms) is substantially reduced.

Let $\mathrm{W} 1$ and $\mathrm{W} 2$ be the values of $\mathrm{W}$ for a given pixel in two successive monthly composites. This pixel is considered as burned if the following conditions are all fulfilled:

I. the pixel belongs to a $3 \times 3$ pixel buffer;

II. $\quad$ W2 $\leq 0.16$;

III. $\Delta \mathrm{W}=\mathrm{W} 2-\mathrm{W} 1 \leq 0.0$.

Estimates of thresholds of $\mathrm{W} 2$ and $\Delta \mathrm{W}$ were obtained by applying classification trees using observed values of $\mathrm{W} 2$ and $\Delta \mathrm{W}$ for burned and unburned pixels in a sample of around 25,000 MODIS pixels covering Amazonia and Cerrado. Figure 2 shows maps of $\mathrm{W}$ for September 2005 composite (left) and of $\Delta \mathrm{W}$ for differences of $\mathrm{W}$ composites between September and August over the study region. It may be noted that areas affected by fire present values of $\mathrm{W}$ well above the prescribed threshold of 0.16 together with negatives values of $\Delta \mathrm{W}$.

\subsection{Selection of burned pixels (stage II)}

Stage II of the selection procedure aims at identifying pixels that although presenting less intense signals in either $\mathrm{W}$ or $\Delta \mathrm{W}$ are likely to be burned ones because of their vicinity to pixels already classified as burned. The weaker radiometric signal may be due to partial burning or to low fire severity. The procedure consists in the following steps: 
I. Let all pixels classified as burnt pixels in stage I be considered as seed points;

II. For each seed point, let $\mathrm{N}$ be the total number of seed points inside a grid of $5 \times 5$ pixels centred at the considered seed point; in case $\mathrm{N}>=3$, let $\hat{\mathrm{W}}$ and $\delta \mathrm{W}$ be the mean and the mean absolute deviation of seed points within the grid. Let $\mathrm{W}^{*}$ be the value of $\mathrm{W}$ for a pixel inside the grid that is not a seed point; this pixel is then classified as a burned pixel and considered as a new seed point if the two following conditions are fulfilled:
a. $\quad \Delta \mathrm{W}^{*}=\mathrm{W}^{*} 2-\mathrm{W}^{*} 1 \leq 0.0$
b. $\quad \mathrm{W}^{*} \leq \hat{\mathrm{W}}+(\delta \mathrm{W})$

III. Step II is recursively performed until no new seed points are generated.

IV. The burned area is obtained by summing up all identified burned pixels.

Figure 3 presents an example of the procedure. It may be noted that most burned pixels are identified in stage I, using the most restrictive criteria; then, during stage II, the number of added burned pixels steeply decreases with the number of iterations.

$$
W_{\text {sep }}
$$
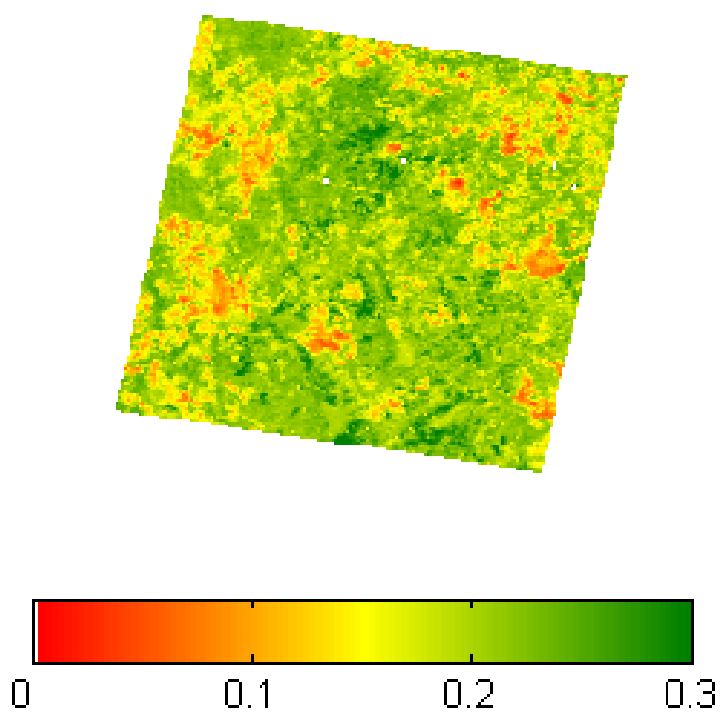

$\Delta W_{\text {sep-aug }}$
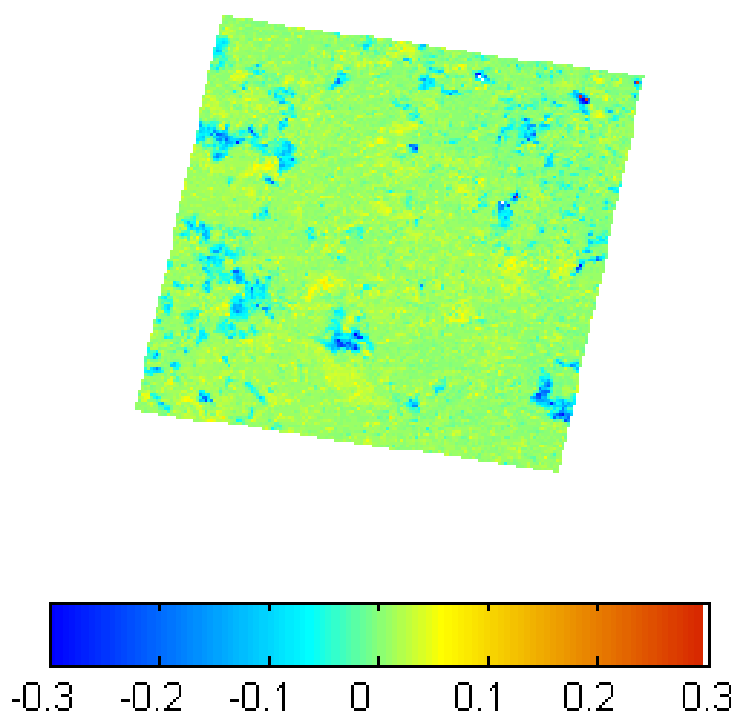

Figure 2. Maps of W for September 2010 composite (left) and of $\Delta W$ between September and August composites over the study region shown in Figure 1. 


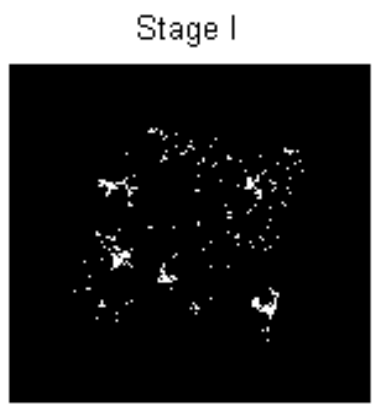

Stage II - iteration ii

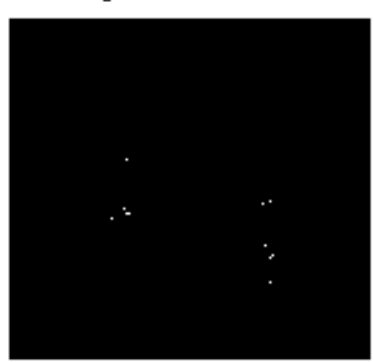

Stage II - iteration i

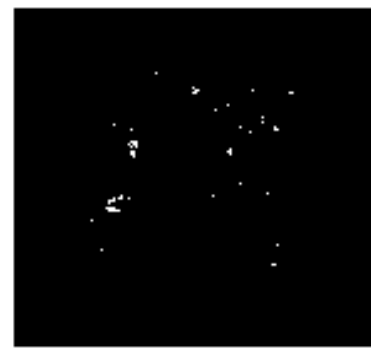

Final

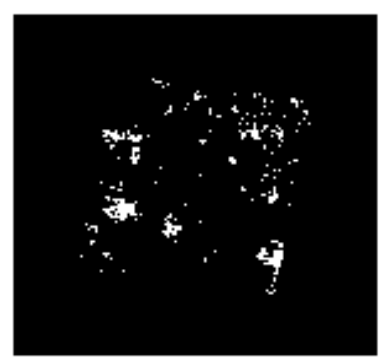

Figure 3. An example of results obtained during stages I and II of the algorithm.

\section{Validation}

The quality of a given thematic map derived from remote sensing is usually assessed based on a systematic comparison with other maps (reference maps) also derived from remote sensing. The evaluation is often made based on contingency tables, also known as confusion or error matrices (Story and Congalton, 1986; Smits et al., 1999; Foody, 2002). Contingency tables (Table 1) provide a very effective means to analyse the number of correctly and incorrectly classified pixels over a study region. The quality assessment will rely on the following four verification measures that may be derived from contingency tables:

1. The overall accuracy (OA), defined as the fraction of correctly classified pixels, either as burned or unburned:

$\mathrm{OA}=(\mathrm{a}+\mathrm{d}) /(\mathrm{a}+\mathrm{b}+\mathrm{c}+\mathrm{d})$

2. The omission error $(\mathrm{OE})$, defined as the fraction of burned pixels in the reference map that were not classified as such in the BA product:

$\mathrm{OE}=\mathrm{c} /(\mathrm{a}+\mathrm{c})$

3. The commission error (COE), defined as the fraction of pixels classified as burned in the BA product that are unburned pixels in the reference map:

$\mathrm{COE}=\mathrm{b} /(\mathrm{a}+\mathrm{b})$

4. The bias (B), defined as the ratio of the number of pixels classified as burned in the BA product to the number of burned pixels in the reference map:

$\mathrm{B}=(\mathrm{a}+\mathrm{b}) /(\mathrm{a}+\mathrm{c})$ 
Whereas OA reflects the agreement between the BA product and the reference map, OE and CE provide information about the reliability and discrimination power of the developed classifier. An unbiased classification exhibits in turn a value of bias equal to one, whereas a bias greater (less) than one indicates the events were over (under) classified.

Table 1. Contingency table for the dichotomous case of pixels classified as burned vs. unburned over a given study region. The total number $n$ of pixels number of pixels is split into four categories with number of occurrences given by $a, b, c$ and $d$.

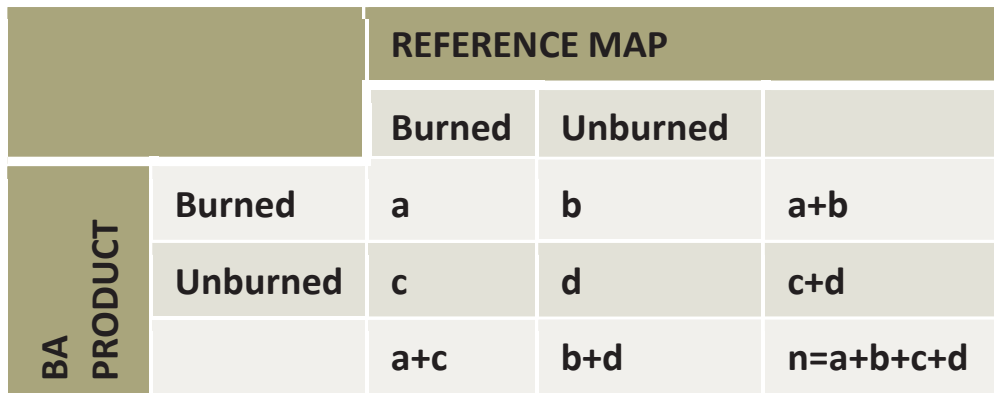

The traditional contingency table assumes that each pixel belongs to a single class; however, several studies (Foody, 1996, 2002; Gong and Howarth, 1990; Karaska et al., 1995) have shown that use of pure pixel approaches is a common source of error in the accuracy assessment of remote sensing products, since reference maps generally have higher resolution than the map being tested. As shown by Binaghi et al. (1999), the problems posed by mixed pixels may be circumvented by using fuzzy theory, which allows each pixel to belong to multiple classes with different degrees of membership. In the present work, the agreement/disagreement between the Landsat TM reference data $(30 \mathrm{~m}$ resolution) and either our product (1 km resolution) and MODIS MCD64A1 and MCD45A1 products (500 $\mathrm{m}$ resolution) are computed taking into account the proportion of BA from reference data within the product pixel. This approach is based on the work by Boschetti et al. (2004) who pointed out the need of taking into account the percentage of BA in each pixel of the coarse product when comparing coarse and high resolution BA maps. For instance, if a pixel is classified as burned by the BA product and has $60 \%$ of BA from reference data, so this pixel will have a proportion of 0.6 as true burned and 0.4 as commission error (as opposed to a weight of 1 as true burned and 0 as commission error that would be assigned following the traditional approach). In the same way, if a pixel is classified as unburned by the BA product and has $20 \%$ of BA from reference data, so this pixel will have a proportion of 0.8 as true unburned and 0.2 as omission error of the non-occurrence. This kind of approach seems to be fairer to the computation of the measures accuracy than the traditional one, since it takes into account the real proportion of reference burned pixel within the product pixel. Recently, Padilla et al. (2014) and Tsela et al. (2014) have conducted similar approaches when validating algorithms for global BA.

\section{Results}

The very own characteristics of the BA product based on the above-described algorithm, hereafter referred to as AQM (from "área queimada", meaning burned area in Portuguese) may be brought into evidence by comparing its performance with the ones of MODIS MCD64A1 and MCD45A1 products. As described in section 3.3, performance of the three products was validated against a reference map of burned scars derived from Landsat TM using verification measures derived from confusion matrices where a mixed-pixel approach is followed that takes into account the proportion of the BA from reference data within the pixel. The same procedure was applied to AQM and the two MODIS global 
products. As described in section 3.1, the study was conducted over Jalapão, for a period of 3 years (2005, 2006 and 2010).

In general, the overall accuracy (OA) for MCD64A1 and MCD45A1 BA products is slightly higher than for AQM (Figure 4); it may be however noted that OA satisfies the principle of equivalence of the events (Wilks, 2006), giving equal credits for burned and unburned classes. This property is not always desirable, particularly in the case of BA detection studies where the burned event is more relevant than the non-occurrence event (unburned event). Both MCD64A1 and MCD45A1 products present very low values of CE but they are affected by quite high values of OE; the two NASA BA products appear therefore as conservative in the sense that a low level of false alarms is attained at the cost of quite high occurrence of omission cases. The AQM product presents in turn a rather low value of $\mathrm{CE}$ together with a clear reduction of $\mathrm{OE}$ that reflects a higher probability of detection of burned pixels. Finally, the AQM product presents an unbiased behaviour $(\mathrm{B} \sim 1)$, whereas the NASA BA products tend to underestimate the number of pixels classified as burned in the reference map $(B<1)$. A better insight into the different characteristics presented by AQM and the two NASA BA products is obtained by looking at the characteristics of pixels correctly classified as burned areas (hits) or contributing to omission and commission errors (Table 2), as obtained when comparing AQM and MODIS MCD64A1 and MCD45A1 versus reference map of burned scars derived from Landsat TM over Jalapão in 2005, 2006 and 2010. Corresponding fractions of pixels located inside (I), on the external border $(\mathrm{B})$ and outside $(\mathrm{O})$ the reference scars were also computed and, for hits and omissions, evaluations were also made of the fractions of low burned pixels (L), i.e. those covered less than 50\% by burned areas in Landsat reference map and of high burned pixels $(\mathrm{H})$, i.e. those covered more than $50 \%$ by burned areas.
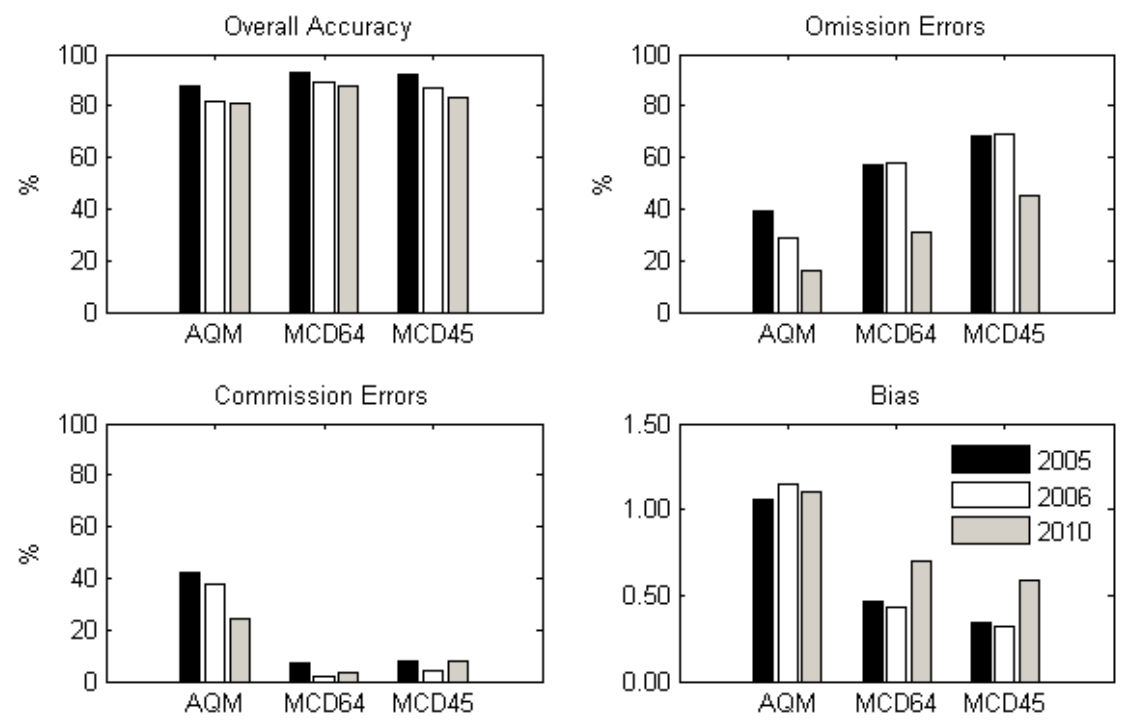

Figure 4. Verification measures as obtained from confusion matrices of AQM and MODIS MCD64A1 and MCD45A1 versus reference map of burned scars derived from Landsat TM over Jalapão in 2005, 2006 and 2010.

As shown in Table 2, for all three products the large majority of hits is associated to pixels located inside burned scars, but the AQM is able to correctly identify a substantially larger number of burned pixels, $30 \%$ of them located in the external borders of the scars (an amount quite larger than those by the NASA products that are below 20\%). On the other hand, the AQM product is able to correctly identify as burned $43 \%$ of pixels with low fraction of burned area (less than 50\%), an amount that is more than the double of that by MCD64A1 (21\%) and almost the double than that by MCD45A1 (23\%). The AQM product presents a substantially lower number of omission errors than the NASA 
products, but for all three products the larger fractions are associated to pixels located in the borders of scars and to pixels with low fraction of burned area (less than 50\%). The very large number of commission errors by AQM also presents a large contrast with the very low number by the two NASA products; however, more than two fifths of commission errors in AQM are associated to occurrences in pixels located in the borders of the scars suggesting that they are not to be viewed as 'false alarms' in the strict sense, but as an overestimation of the size of the real scars. This problem is likely to be associated to errors in geo-referencing of a small number of MODIS images that propagate into the multi-image composites. Obtained results may be visually confirmed in Figure 5 that shows pixels where true burned areas were detected (green), together with omission (blue) and commission (red) errors from AQM (left) and MCD64A1 (right) in Jalapão during 2010. The AQM product shows higher probability of detection of burned pixels, i.e. lower OE than MCD64A1 that presents a higher value of $\mathrm{OE}$ and a very low value of CE. A large fraction of pixels with commission errors in AQM are located in the external borders of the scars (delimited by the black lines).

Table 2. Number of hits, omission errors and commission errors when comparing AQM and MODIS MCD64A1 and MCD45A1 versus reference map of burned scars derived from Landsat TM over Jalapão in 2005, 2006 and 2010 together with corresponding fractions of pixels located inside (I), in the external border (B) and outside (O) the scars in reference maps and, for hits and omissions, the fractions of low burned pixels $(L)$, i.e. covered less than $50 \%$ by burned areas in Landsat reference map and of high burned pixels $(H)$, i.e. covered more than $50 \%$ by burned areas.

\begin{tabular}{|c|c|c|c|}
\hline & Hits & Omissions & Commissions \\
\hline \multirow{3}{*}{ AQM } & 15961 & 12649 & 7466 \\
& $\mathrm{I}=70 \% ; \mathrm{B}=30 \%$ & $\mathrm{I}=42 \% ; \mathrm{B}=58 \%$ & $\mathrm{O}=59 \% ; \mathrm{B}=41 \%$ \\
& $\mathrm{~L}=43 \% ; \mathrm{H}=57 \%$ & $\mathrm{~L}=64 \% ; \mathrm{H}=36 \%$ & \\
\hline \multirow{3}{*}{ MCD64A1 } & 9492 & 19118 & 325 \\
& $\mathrm{I}=82 \% ; \mathrm{B}=18 \%$ & $\mathrm{I}=46 \% ; \mathrm{B}=54 \%$ & $\mathrm{O}=51 \% ; \mathrm{B}=49 \%$ \\
& $\mathrm{~L}=21 \% ; \mathrm{H}=79 \%$ & $\mathrm{~L}=67 \% ; \mathrm{H}=33 \%$ & \\
\hline & 7132 & 21478 & 545 \\
MCD45A1 & $\mathrm{I}=81 \% ; \mathrm{B}=19 \%$ & $\mathrm{I}=50 \% ; \mathrm{B}=50 \%$ & $\mathrm{O}=43 \% ; \mathrm{B}=57 \%$ \\
& $\mathrm{~L}=23 \% ; \mathrm{H}=77 \%$ & $\mathrm{~L}=62 \% ; \mathrm{H}=38 \%$ & \\
\hline
\end{tabular}
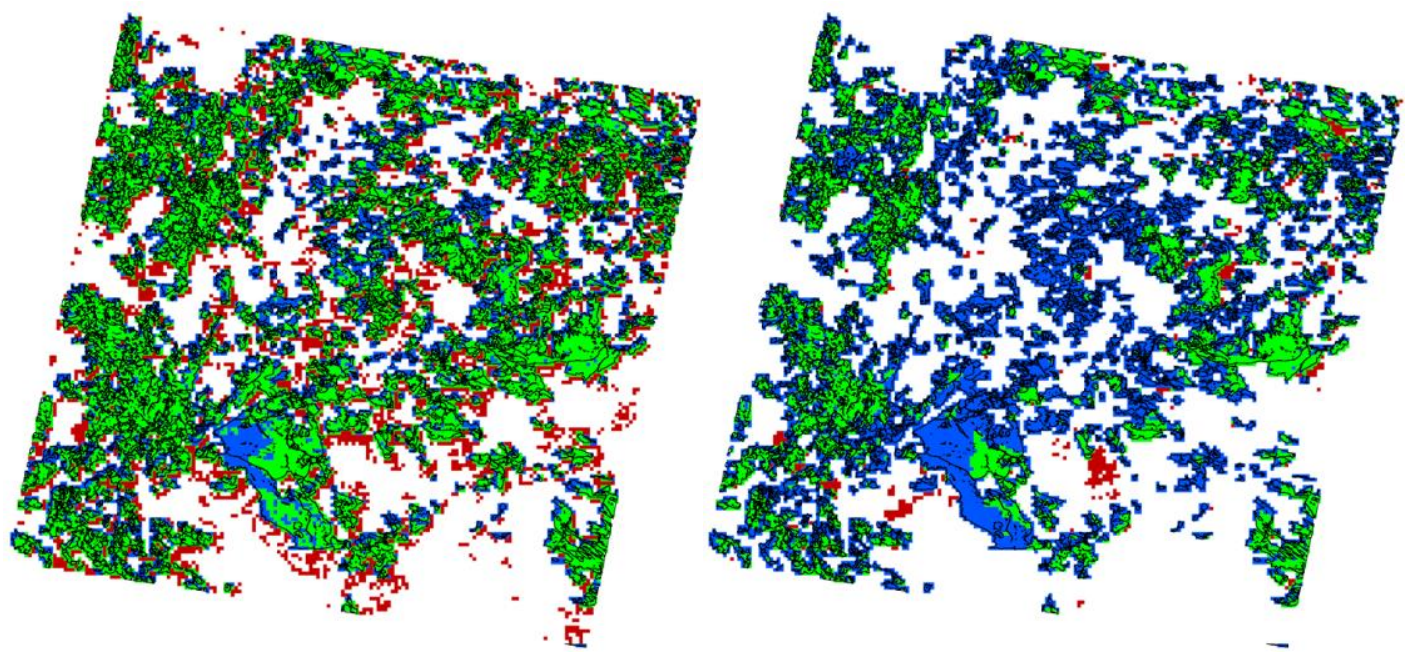

Figure 5. Maps showing pixels where true burned areas were detected (green), together with omission (blue) and commission (red) errors. TM reference scars (black lines) are superimposed. Results shown are those obtained from AQM (left panel) and MCD64A1 (right panel) over Jalapão in 2010. 
As shown in Table 3, during the three years analysed the area of study was characterized by high frequency $(87-90 \%)$ of small scars $(<100 \mathrm{ha})$ that accounts for a small percentage $(8-19 \%)$ of the total BA. Large scars (> 1000ha) are rare (1-2\%) but they account for a large amount $(42-64 \%)$ of the total BA. As opposed to regions where large scars are predominant, low resolution instruments will tend to underestimate BA in regions where burned scars are small and fragmented. A large number of omission errors in therefore to be expected It is therefore to be expected in all three analysed products (Table 2) but, as already pointed out, the AQM is able to identify a larger fraction of low burned pixels than the NASA products. The AQM product appears therefore as more sensitive to sub-pixel burned areas, even when working at a lower spatial resolution $(1 \mathrm{~km})$ than the NASA products $(500 \mathrm{~m})$; this is probably due to the use of MIR reflectance by the algorithm.

Table 3. Fractions of total number of scars and of total burned area for three classes of scars as derived from Landsat TM data over Jalapão in 2005, 2006 and 2007.

\begin{tabular}{|c|c|c|c|}
\hline \multirow{2}{*}{2005} & Classes & $\begin{array}{c}\text { Fraction of total } \\
\text { number of scars }\end{array}$ & $\begin{array}{c}\text { Fraction of total burned } \\
\text { area }\end{array}$ \\
\cline { 2 - 4 } & $\mathbf{1 0 0 0 h a}$ & $90 \%$ & $16 \%$ \\
\cline { 2 - 4 } & $\mathbf{1 0 0 - 1 0 0 0 h a}$ & $9 \%$ & $38 \%$ \\
\hline \multirow{3}{*}{2006} & $>\mathbf{1 0 0 0 h a}$ & $1 \%$ & $46 \%$ \\
\cline { 2 - 4 } & $\mathbf{1 0 0 - 1 0 0 0 h a}$ & $89 \%$ & $19 \%$ \\
\cline { 2 - 4 } & $>\mathbf{1 0 0 0 h a}$ & $10 \%$ & $39 \%$ \\
\hline \multirow{3}{*}{2010} & $<100$ ha & $87 \%$ & $42 \%$ \\
\cline { 2 - 4 } & $\mathbf{1 0 0 - 1 0 0 0 h a}$ & $11 \%$ & $8 \%$ \\
\cline { 2 - 4 } & $>\mathbf{1 0 0 0 h a}$ & $2 \%$ & $27 \%$ \\
\hline
\end{tabular}

\section{Conclusions}

An automated regional algorithm able to detect burned areas in Brazilian biomes was developed using information from MODIS imagery at $1 \mathrm{~km}$ resolution. The algorithm relies on the so-called W burning index that is defined in a transformed NIR-MIR space. Pixels are classified as burned ones when there is a change in $\mathrm{W}$ between 30-day composites that are likely to have been induced by a fire event. Identification of burned pixels is performed in two stages. First, the algorithm is restricted to pixels belonging to buffer zones centred in pixels where active fires were identified from a variety of sensors on-board geostationary satellites and polar orbiters. Then the algorithm is successively applied to pixels in the vicinity of pixels that were classified as burned.

The resulting AQM product was validated against reference maps of scars derived from Landsat TM images over a study region located in the Cerrado biome. For purposes of performance assessment, two operational NASA products, MCD64A1 and MCD45A1, were also validated against the same reference maps. Because the products to be validated have different spatial resolutions than that of reference maps (e.g. AQM with $1 \mathrm{~km}$ and Landsat scars with $30 \mathrm{~m}$ ), the error matrix was estimated following a new approach based on the assumption of mixed pixels, where the agreement/disagreement between product and reference data are computed taking into account the proportion of BA from reference data within the product pixel.

The two NASA products present very low commission errors (ranging from 2 to $10 \%$ ) but also very high occurrence of omission errors (greater than $60 \%$ in almost all cases analysed). The AQM product has larger commission errors (ranging from 20 to 40\%) but a large fraction of those (more than 40\%) 
occur at the borders of the scars and may therefore not be strictly viewed as false alarms; there is also a clear reduction of the omission cases (below $40 \%$ in all cases).

Performance of the AQM product may be attributed to two main factors. On the first hand, the usage by the algorithm of the $\mathrm{W}$ index, that was specifically designed to identify burned areas and takes advantage of the ability of MIR reflectances to discriminate burned areas. On the second hand, the usage of multiple sensor active fire observations that considerably contribute to mitigating the problem of failing to uncover BA due to active fire omissions either because of the time of satellite overpass or due to obscuration by clouds, smoke and vegetation. It is worth mentioning that active fire information from NPP/VIIRS (which is being disseminated by INPE since 25/09/2013) is also planned to be introduced operationally in the algorithm, contributing to increase the spatial and temporal coverage of fire observations.

The AQM approach is currently in pre-operational phase at INPE and additional tuning experiments are currently being carried on. More validation sites are also being developed at INPE using Landsat TM imagery that will allow performing accuracy assessments of the algorithm for different biomes.

\section{Acknowledgments}

Research was supported by the scientific grants FAPESP 2010/19712-2 and CNPq 309199/2008-5, and the GIZ - German Technical Cooperation Agency through the MMA Project "Prevenção, controle e monitoramento de queimadas irregulares e incêndios florestais no Cerrado". Research was also supported by the EU 7th Framework Program (FUME) contract number 243888.

\section{References}

Barbosa, P. M., Pereira, J. M. C., and Gregoire, J.-M. (1998). Compositing criteria for burned area assessment using multitemporal low resolution satellite data. Remote Sens. Environ., 65, 38- 49.

Binaghi, E., Brivio, P. A., Ghezzi, P., and Rampini, A. (1999). A fuzzy set-based accuracy assessment of soft classification.Pattern Recognition Letters, 20, 935-948.

Boschetti, L., Flasse, S.P., and Brivio, P.A. (2004). Analysis of the conflict between omission and commission in low spatial resolution dichotomic thematic products: The Pareto Boundary. Remote Sens. Environ., 91, 280-292.

Chuvieco, E., Englefield, P., Trischenko, A., and Lio, Y. (2008). Generation of long time series of burn area maps of the boreal forest from NOAA-AVHRR composite data. International Journal of Remote Sensing, 23, 5103-5110.

Fraser, R. H., Li, Z., and Cihlar, J. (2000). Hotspot and NDVI differencing synergy (HANDS): A new technique for burned area mapping over boreal forest. Remote Sens. Environ., 74, 362-376.

Foody, G.M. (1996). Approaches for the production and evaluation of fuzzy land cover classications from remotely-sensed data .Internat. J. Remote Sensing, 17(7), 1317-1340.

Foody, G.M. (2002). Status of land cover classification accuracy assessment. Remote Sens. Environ., 80,185-201.

George, C., Rowland, C., Gerard, F., and Balzter, H. (2006). Retrospective mapping of burnt areas in Central Siberia using a modification of the normalized difference water index. Remote Sens. Environ., 104, 346-359.

Giglio, L., Loboda, T., Roy, D. P., Quayle, B., and Justice, C. O. (2009). An active-fire based burned area mapping algorithm for the MODIS sensor, Remote Sens. Environ., 113, 408-420.

Giglio, L., van der Werf, G. R., Randerson, J. T., Collatz, G. J., and Kasibhatla, P. S. (2006). Global estimation of burned area using MODIS active fire observations. Atmospheric Chemistry and Physics, 6, 957-974. 
Gong, P., and Howarth, P. J. (1990). The use of structural information for improving land-cover classification accuracies at the rural -urban fringe.Photogrammetric Engineering and Remote Sensing, 56, 67-73.

Karaska, M. A., Huguenin, R. L., Van Blaricom, D., and Savitsky, B. (1995). Subpixel classification of cypress and tupelo trees in TM imagery. Proceedings of the 1995 ACSM/ASPRS Annual Convention and Expo-sition, 3, 856-865.

Kaufman, Y. J., and Remer, L. (1994). Detection of forests using mid-IR reflectance: An application for aerosol studies. IEEE Trans. Geosci. Remote Sens., 32(3), 672-683.

Libonati, R., DaCamara, C. C., Pereira, J. M. C., and Peres, L. F. (2011). On a new coordinate system for improved discrimination of vegetation and burned areas using MIR/NIR information. Remote Sens. Environ., 114, 831-843.

Loboda, T., O'Neal, K. J., and Csiszar, I. (2007). Regionally adaptable dNBR-based algorithm for burned area mapping from MODIS data. Remote Sensing of Environment, 109, 429-442.

Padilla, M., Stehman, S.V., Litago, J., Chuvieco, E. (2014). Assessing the temporal stability of the accuracy of a time series of burned area products. Remote Sens., 6, 2050.2068.

Pereira, J. M. C. (1999). A comparative evaluation of NOAA/AVHRR vegetation indexes for burned surface detection and mapping. IEEE Trans. Geosci. Remote Sens., 37(1), 217-226.

$\mathrm{Pu}$, R., Gong, P., Li, Z., and Scarborough, J. (2004). A dynamic algorithm for wildfire mapping with NOAA/AVHRR data. International Journal of Wildland Fire, 13, 275-285.

Roy, D. P., Giglio, L., Kendall, J. D., and Justice, C. O. (1999). Multi-temporal active-fire based burn scar detection algorithm. International Journal of Remote Sensing, 20, 1031-1038.

Roy, D.P., Jin, Y., Lewis, P.E., e Justice, C.O. (2005). Prototyping a global algorithm for systematic fire-affected area mapping using MODIS time series data. Remote Sens. Environ., 97(2), 137-162.

Schroeder, W., Csiszar, I., and Morisette, J. (2008). Quantifying the impact of cloud obscuration on remote sensing of active fires in the Brazilian Amazon. Remote Sens. Environ., 112, 456-470.

Schroeder, W., Morisette, J., Csiszar, I., Giglio, L., Morton, D., Justice, C.O., (2005) Characterizing Vegetation Fire Dynamics in Brazil through Multisatellite Data: Common Trends and Practical Issues. Earth Interact., 9, 1-26.

Smits, P.C., Dellepiane, S.G., and Schowengerdt, R.A. (1999). Quality assessment of image classification algorithms for land-cover map-ping: A review and a proposal for a cost-based approach. International Journal of Remote Sensing, 20:1461-1486.

Sousa, A. M. O., Pereira, J. M. C.. and Silva, J. M. N., (2003). Evaluating the performance of multitemporal image compositing algorithms for burned area analysis. International Journal of Remote Sensing 24(6): 1219-1236.

Story, M., and Congalton, R.G. (1986). Accuracy assessment: A user's perspective, Photogrammetric Engineering and Remote Sensing, 52:397-399.

Stroppiana, D., Pinnock, S., Pereira, J.M.C, and Gregoire, J-M. (2002). Radiometric analysis of SPOTVEGETATION images for burnt area detection in Northern Australia. Remote Sens. Environ., 82, 21-37.

Stroppiana, D., Tansey, K., Gregoire, J-M. and Pereira, J.M.C, (2003). An algorithm for mapping burnt areas in Australia using SPOT-VEGETATION data, IEEE Trans. Geosci. Remote Sens., 41, 4,.907 $-909$.

Tsela, P., Wessels, K., Botai, J., Archibald, S., Swanepoel, D., Steenkanp, K., Frost, P. (2014). Validation of the tow standard MODIS satellite burned area products and an Empirically-derived merged product in South Africa. Remote Sens, 6, 1275-1293.

Wilks, D. (2006). Statistical methods in the atmospheric sciences. Second Edition. Academic Press, pp 627. 